Journal of

\title{
Analysis of Stem-Cell and Migratory Phenotype in Primary Cultures Derived From BPV-Infected Benign and Malignat Neoplasms
}

Rodrigo Pinheiro Araldi ${ }^{1,2}$, Thaylene Alexandra do Nascimento Lima ${ }^{1}$, Diego, Grando Módolo ${ }^{1}$, Jacqueline Mazzuchelli de Souza ${ }^{1,2}$, Roberta Fiusa Magnelli ${ }^{1,2}$, Beatriz Maurício ${ }^{3}$, Diva Denelle Spadacci Morena $^{4}$, Paulo Luiz de Sá Júnior ${ }^{1}$, Rodrigo Franco de Carvalho ${ }^{1}$, Willy Beçak ${ }^{1}$, Rita de Cassia Stocco ${ }^{1, *}$

${ }^{1}$ Genetics Laboratory, Butantan Institute, São Paulo, Brazil

${ }^{2}$ Interunit Post-graduation Program in Biotechnology, Biomedicine Institute, University of São Paulo (USP), São Paulo, Brazil

${ }^{3}$ Cell Biology Laboratory, Butantan Institute, São Paulo, Brazil

${ }^{4}$ Physiopathology Laboratory, Butantan Institute, São Paulo, Brazil

${ }^{*}$ Corresponding author: Rita de Cassia Stocco, Genetics Laboratory, Butantan Institute, São Paulo, Brazil; e-mail: rita.stocco@butantan.gov.br Phone/Fax: +55 (011) 2627-9701

Received Date: February 03, 2017; Accepted Date: February 09, 2017; Published Date: February 11, 2017

Citation: Rodrigo Pinheiro Araldi, et al. (2017) Analysis of Stem-Cell and Migratory Phenotype in Primary Cultures Derived From BPVInfected Benign and Malignat Neoplasms. J Cancer Res Therap Oncol 5: 1-13.

\begin{abstract}
Bovine papillomavirus (BPV) is the etiological agent of bovine papillomatosis, neoplastic disease that can regress spontaneously or persist, resulting in malignances such as urinary bladder and esophageal carcinoma (EC). Although recognized as cancer initiator, BPV action during metastasis remains unclear. This study evaluated the acquisition of stem-cell and migratory phenotype in primary cultures derived from BPV-infected neoplams. For this, five primary cell cultures were used: BPV-free normal skin (negative control), skin papilloma (papilloma 01), fibropapilloma (papilloma 02 and 03) and EC. These cells were cultivated until sixth passage (P1-P6). The acquisition of stem-cell phenotype was analyzed by tumorsphere formation assay and by the Oct-3/4 transcription factor expression levels. Morphological analysis was performed by phase contrast and screen electron microscopy (SEM). Results showed that all BPV-infected primary cultures were able to form tumorspheres, which were not verified in BPV-free normal skin cells. Skin papilloma, fibropapilloma and EC cells also showed high levels of Oct-3/4 expression in relation to normal skin. BPV-infected cells show loss of apical-basal polarity, lamellipodia and filopodia, which were confirmed by SEM and F-actin labelling. Time-lapse video microscopy showed that EC and papilloma 03 presented the highest migration velocity, while papilloma 01 , an intermediate velocity. Statistical analysis did not revealed significant differences between the normal skin and papilloma 02 (fibropapilloma) migration velocity. These results suggest that BPV not only act during cancer initiation, but also during metastasis.
\end{abstract}

Keywords: Bovine papillomavirus (BPV); Culture cell; Stem-cell; Cell migration; Epithelial-mesenchymal transition (EMT)

Abbreviations: BPV: Bovine Papillomavirus, CSC: Cancer Stem-Cell, EMT: Epithelial-Mesenchymal Transition, HPV: Human Papillomavirus, SEM: Screen Electron Microscopy

\section{Introduction}

Bovine papillomavirus (BPV) is the etiopathogenic agent of bovine papillomatosis, an infectious and neoplastic disease characterized by multiple benign neoplasms (papillomas) that can regress spontaneously, but may also persist leading to urinary bladder and esophageal carcinoma when in presence of co-factors [1-4]. BPV is also considered a useful model to study the HPV-associated oncogenic process, once these vi-

(C)2017 The Authors. Published by the JScholar under the terms of the Creative Commons Attribution License http://creativecommons.org/licenses/ by/3.0/, which permits unrestricted use, provided the original author and source are credited. ruses share morphological and pathogenic characteristics in common [5-7]. For this reason, virologists have used BPV as a model for the study of HPV infection and interaction with the host cell [8].

Although studies had demonstrated that both BPV [1,2,9-11] and HPV induce DNA damages, can lead to genomic instability and cancer initiation $[12,13]$, there are few works about the action of these viruses in metastasis, which is responsible for about $90 \%$ of all cancer-related deaths globally [6]. 
Metastatic process consists of a long series of sequential and interrelated steps in which cancer cells from primary neoplasm spread to distant organs [14]. During this process, it is verified biochemical, genetics and morphological changes that epithelial-mesenchymal transition (EMT), a biological reprogramming process which confers migratory and invasiveness capability do transformed cells $[6,15]$. The lack of studies involving the papillomaviruses (PVs) participation in EMT can be attributed to the little attention given to primary cultures derived from PVs-infected neoplasms. In this sense, our group has showed that primary cultures derived from BPV-infected neoplasms are useful models to study the genetic [9] and biochemical deregulations, contributing to genomic instability and cell transformation [7]. Genomic instability is pointed out as responsible to induce the cancer stem-cell (CSC) phenotype acquisition [16-18], repressing reversibly the expression of cell differentiation genes [19], contributing to EMT and metastasis [20]. Considering that we first reported genetic and biochemical changes in BPV-infected cells derived from neoplasms, in this study we analyzed the acquisition of CSC phenotype, as well as the invasiveness capability of primary culture cells derived from cutaneous papilloma, fibropapilloma and esophageal carcinoma.

\section{Materials and Methods}

\section{Ethics statement}

This study was approved by the Ethics Committee of Butantan Institute under process 1319-14.

\section{Primary cell cultures}

Primary cells cultures used was obtained by Campos et al. (2013) from fragments of: normal skin, showing no morphological alteration, skin papilloma (papilloma 01), fibropapilloma (papilloma 02 and 03) and esophageal carcinoma. These tissues were collected from adult bovines (Bos taurus). Cells were seeded in culture flasks of $25 \mathrm{~cm} 2$, containing $5 \mathrm{~mL}$ of complete medium: DMEM medium (Cultilab, Brazil), supplemented with 15\% fetal bovine serum (Cultilab, Brazil) and $1 \%$ ampicillin-streptomycin (Cultilab, Brazil). Cells were incubated at $37^{\circ} \mathrm{C}$, in $5 \%$ of $\mathrm{CO} 2$ atmosphere up to $80 \%$ confluence (about 72 hours). Cells were cultivated until the sixth passage (P1-P6). Molecular identification of BPV was performed by PCR using specific primers for BPV-1 and 2, considered the most frequent virus types [21] and, BPV-4, due its association with upper gastric papilloma and carcinoma [9,22]. PCR results were already published in Araldi et al.(2016 a), demonstrating the BPV infection in primary cell cultures of papilloma 01, 02, 03 and esophageal carcinoma, but not in normal skin. These results are summarized in table 1.

\section{Analysis of stem-cell phenotype}

\section{Tumorsphere formation assay}

Cells were subjected to the tumorsphere formation assay, method considered "gold-standard" to identify the acquisition of stem-cell phenotype $[23,24]$.
For this, $5 \times 105$ cells in second passage (P2) were transferred to six-well plate pre-covered with $1 \mathrm{~mL}$ of $2 \%$ agarose, diluted in sterile PBS and $2 \mathrm{~mL}$ of complete medium. Cells were incubated at $37^{\circ} \mathrm{C}$ with $5 \% \mathrm{CO} 2$ atmosphere for 24 hours. Next, the cells were analyzed in Nikon Eclipse Ti inverted microscope and images were captured in total magnification of 100X.

\section{Immunodetection of Oct-3/4 transcription factor} Immunofluorescence: a total of 1 x 105 cells in second passage (P2) were seeded per well, employing a six-well plate, containing $2 \mathrm{~mL}$ of complete DMEM medium and a $24 \times 24 \mathrm{~mm}$ sterile cover slip. Cells were incubated at $37^{\circ} \mathrm{C}$, with $5 \% \mathrm{CO} 2$ atmosphere, until a confluency of $80 \%$ (about 24 hours). The medium was removed and cells were washed three times with sterile $\mathrm{PBS}$ at $37^{\circ} \mathrm{C}$ for five minutes. Cells were fixated with $4.0 \%$ formalin, diluted in PBS, at $4^{\circ} \mathrm{C}$ for 30 minutes and then washed three times with PBS at $37^{\circ} \mathrm{C}$ for 5 minutes. Cells were permeabilized with $0.01 \%$ Triton X-100 (Sigma, Germany), diluted in PBS, at $4^{\circ} \mathrm{C}$ for 10 minutes. Cells were washed once with PBS and incubated overnight at $4{ }^{\circ} \mathrm{C}$, in a moist chamber with polyclonal antibody anti-Oct-3/4 $\mathrm{H}-65$ produced in rabbit (Santa Cruz Biotechnology, USA) at 1:100 dilution in 1\% bovine serum albumin (BSA). Cells were washed three times with PBS for five minutes and then incubated at $4^{\circ} \mathrm{C}$ for 3 hours with anti-rabbit IgG conjugated with FITC (Sigma, Germany) at 1:200 dilution in 1.0\% BSA. Cells were washed three times with PBS and cover slips were mounted on slides, using 20 $\mu \mathrm{L}$ of ProLong Gold (Invitrogen, Carlsbad, USA) with DAPI. Slides were analyzed in Axio Scope A1 fluorescent microscope (Carls Zeiss, Germany) under total magnification of 400X.

Flow cytometry: Cell lines were seeded in culture flasks of 25 $\mathrm{cm} 2$ with $5 \mathrm{~mL}$ of complete DMEM medium. Cells were subjected to monolayer disaggregation with $2 \mathrm{~mL}$ of EDTA solution and centrifuged at 1,700 rpm for 5 minutes. Cells were transferred to $1.5 \mathrm{~mL}$ polypropylene tubes and fixed in 1.0 $\mathrm{mL}$ of $1.0 \%$ formalin solution at $4^{\circ} \mathrm{C}$ for 2 hours. Cell suspension was centrifuged and washed twice with $1.0 \mathrm{~mL}$ of PBS at $4^{\circ} \mathrm{C}$ to remove the formalin residues. Cell were incubated with $1.0 \% \mathrm{BSA}$ at $4^{\circ} \mathrm{C}$ for 20 minutes, washed once with PBS, and incubated overnight at $4^{\circ} \mathrm{C}$ with $1.0 \mu \mathrm{L}$ of anti-Oct-3/4 produced in rabbit (Santa Cruz Biotechnology, USA). Cells were centrifuged under described conditions, washed twice with PBS and incubated at $4^{\circ} \mathrm{C}$ for 2 hours with anti-rabbit conjugated with Alexa Fluor 488 secondary antibody (Invitrogen, Carlsbad, USA) at 1:200 dilution in 1\% BSA. Next, cells were washed with PBS, centrifuged and resuspended in 100 $\mu \mathrm{L}$ of PBS. The material was analyzed in Accuri C6 cytometer (BD Bioscience, USA), employing the FL1 channel. A total of 10,000 events were analyzed. Results were analyzed in FlowJo software (TreeStar, Oregon, USA), using the percentage of immune-labeled cells. Skin papilloma cell line incubated with only secondary antibody was used as control for immunofluorescence and flow cytometry. 
Table 1: BPV types identified in primary cell cultures

\begin{tabular}{|l|l|l|l|l|l|l|}
\hline & Passage 1 & Passage 2 & Passage 3 & Passage 4 & Passage 5 & Passage 6 \\
\hline Normal skin & - & - & - & - & - & \\
\hline Papilloma 01 & BPV-1 & BPV-1 and 2 & BPV-2 & BPV-1 and 2 & BPV-1 and 2 & - \\
\hline Papilloma 02 & BPV-1, 2 and 4 & BPV-1, 2 and 4 & BPV-2 and 4 & BPV-1 and 2 & BPV-1, 2 and 4 & BPV-2 and 4 \\
\hline Papilloma 03 & BPV-2 and 4 & BPV-1 and 2 & BPV-2 & BPV-2 and 4 & BPV-1 and 2 & BPV-2 \\
\hline Carcinoma & BPV-1, 2 and 4 & BPV-1, 2 and 4 & BPV-1, 2 and 4 & BPV-1, 2 and 4 & BPV-1, 2 and 4 & BPV-1, 2 and 4 \\
\hline
\end{tabular}

Results based on Araldi et al. [7]

\section{Analysis of stem-cell phenotype}

\section{Morphological analysis}

Morphological analysis of six passages (P1-P6) was performed using a phase contrast microscopy, employing the Nikon Eclipse Ti inverted microscope (Nikon, Japan) in total magnification of $100 \mathrm{X}$. This method was used to identify morphological alterations suggestive of migratory phenotype, such as lamellipodia and filopodia, which are directly associated to cell migration and EMT. To better visualize the ultrastructure of these organelles, cell lines in fourth passage (P4) were subjected to screen electronic microscopy (SEM). Cell lines were seeded in six-well plate containing a 24 x $24 \mathrm{~mm}$ sterile cover slip and $2 \mathrm{~mL}$ of complete DMEM medium up the $80 \%$ of confluence. Medium was removed and cells were washed three times with sterile PBS at $4^{\circ} \mathrm{C}$. Cells were fixated in $1 \mathrm{~mL}$ of Karnovsky fixative (50 mL 8\% paraformaldehyde, $10 \mathrm{~mL}$ $25 \%$ glutaraldehyde, $40 \mathrm{~mL} 0.2 \mathrm{M}$ PBS, $\mathrm{pH} 7.3$ ), processed and analyzed in Quanta 250 (Fei Company, Holland) in a primary beam accelerated at $10-15 \mathrm{~V}$ in different magnifications.

\section{F-actin labelling}

To confirm the presence of filipodia, cells were labelled with phalloidin and analyzed by High-content screening (HCS). Cells were expanded in 96-well plate (Corning, USA), using DMEM complete medium until to obtain $5 \times 103$ cells $/ \mathrm{cm} 3$. Cells were fixed in $4 \%$ paraformaldehyde and washed three times with PBS. Cells were permeabilized with $0.1 \%$ Triton X-100 (Sigma, Germany) diluted in PBS for 10 minutes and labelled with phalloidin (Sigma, Germany). Cells were washed three time with PBS and the nucleus were labelled with $0.1 \mathrm{~g} / \mathrm{mL}$ of Hoechst 33342 (Molecular Probe, USA) for 10 minutes. The plates were analyzed in HSC (Molecular Devices, USA) and the imagens were captured using the software MicroHCS (Molecular Devices, USA).

\section{Time-lapse microscopy for cell migration}

Cell migration was analyzed by time-lapse video microscopy, employing the InCell Analyzer 2200 (GE Healthcare, USA). A total of $200 \mu \mathrm{L}$ of DMEM complete medium were transferred to six-well plates. A total of 2 x 105 cells in second passage (P2) was transferred per well.
The plate was incubated at $37^{\circ} \mathrm{C}$, with $5 \% \mathrm{CO} 2$, and one picture was taken every 15 minutes, completing a total of 80 time-points (20 hours). The images were analyzed using the Image $1.5 \mathrm{e}$ software, and the average speed, in $\mu \mathrm{m} /$ minute, of each time-point in a total of five cells per cell line was calculated. Based on these values, it was performed the analysis of variance (ANOVA), followed by the Tukey test, both with 5\% of significance level, using the GraphPad Prism 5.0.

\section{Results}

\section{Acquisition of stem-cell phenotype}

Results of tumorsphere formation assay showed the presence of spheroidal cellular aggregates in primary cell cultures of skin papilloma, fibropapilloma and esophageal carcinoma, but not in normal skin cell line (figure 1). To confirm the acquisition of stem-cell phenotype, we analyzed the Oct-3/4 transcription factor expression levels by flow cytometry. Results of this analysis showed an increase in Oct-3/4 expression in all BPV-infected primary cultures in relation to normal skin cells (figure 2). We also verified the Oct-3/4 nuclear labelling in esophageal carcinoma cells by immunofluorescence analysis (figure 3).

\section{Acquisition of migratory phenotype}

Morphological analysis by phase contrast microscope showed the loss of cell apical-basal polarity and the presence of lamellipodia and filopodia in skin papilloma, fibropapilloma and esophageal carcinoma cells (figure 4). The presence of filopodia was confirmed by the F-actin labelling (figure 5). These alterations were verified along the six passages analyzed, suggesting the acquisition of migratory phenotype. By the contrast, normal skin cell showed the preservation of cell polarity along the passages. The loss of polarity and the filopodia presence in all BPV-infected cells were confirmed by SEM analysis (figure 6). This analysis also showed the presence of inter-cytoplasmic bridges in fibropapilloma (figure $6 \mathrm{H}$ ) and esophageal carcinoma (figure 6I) cells, suggesting a possible mechanism of horizontal genetic transfer. To verify the migratory capability of these cells, we performed the time-lapse video microscopy, obtaining the average speed of 5 cells/primary culture along 20 hours in a total of 80 time-points. Based on the speed average of each primary cell culture (figure 7), we performed the parametric ANOVA, that showed statistical differences among the cell migration velocity $(\mathrm{p}<0.0001)$. 
Figure 1 - Results of tumorsphere formation assay

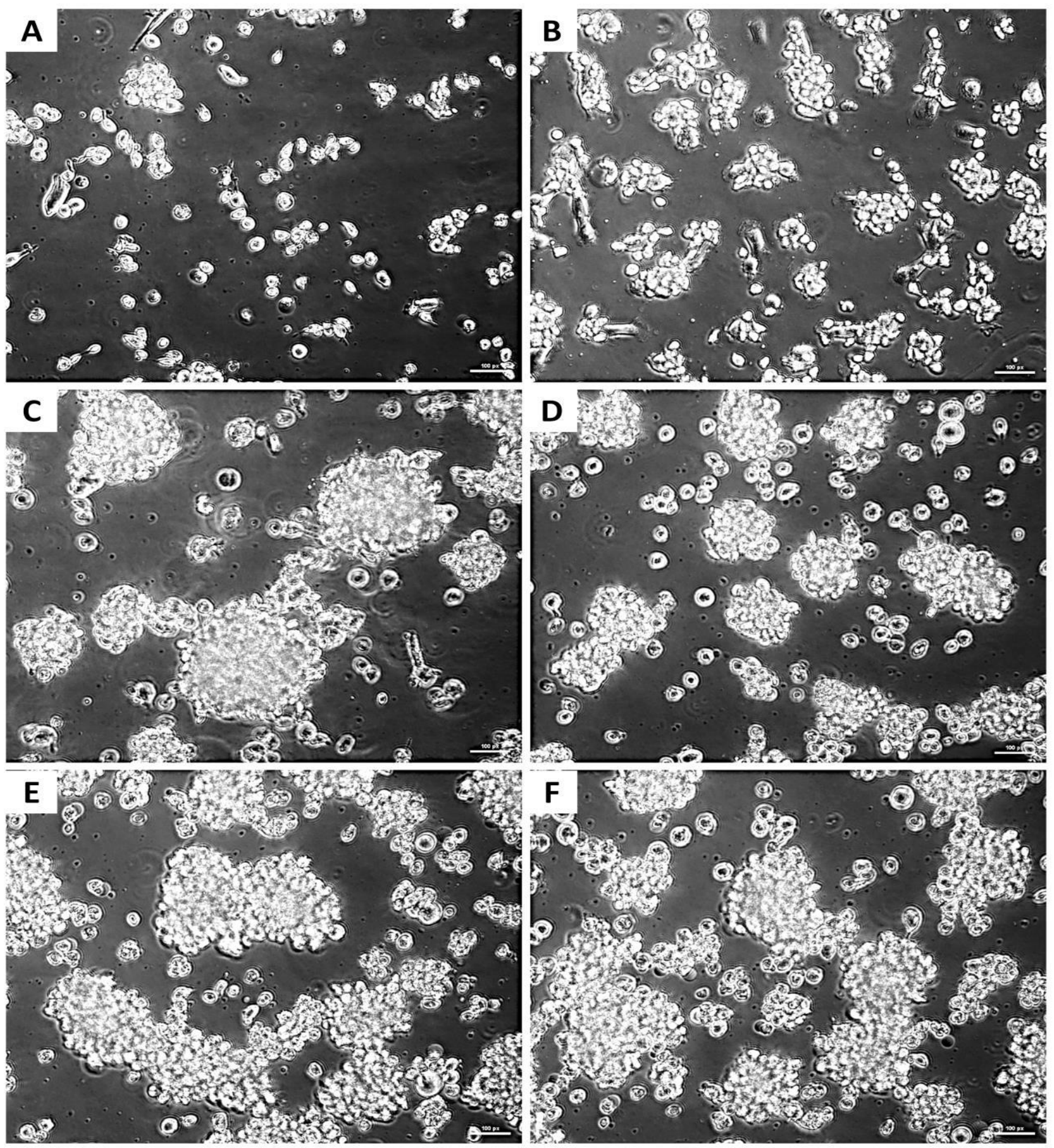

Results of tumorsphere formation assay showing the absence of spheroidal cellular aggregates (tumorspheres) in normal skin cell line (A) and the presence of tumorspheres in skin papilloma (B, papilloma 01 ), fibropapilloma (C, papilloma 02 and $\mathrm{D}$, papilloma 03) and esophageal carcinoma cell lines (E and F). Total magnification of $100 \mathrm{X}$. Scale bar of $100 \mu \mathrm{m}$. 
Figure 2 - Quantitative analysis of Oct-3/4 transcription factor by flow cytometry

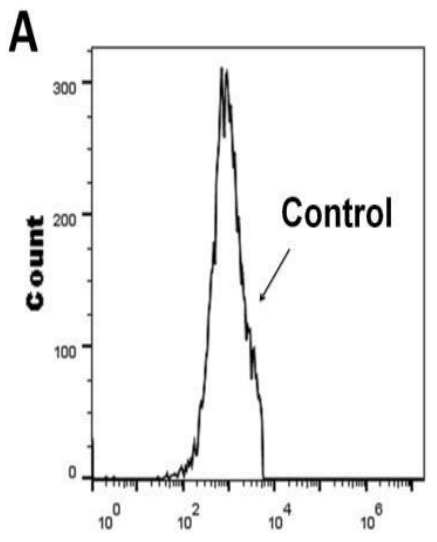

FL1-H : FL1-H

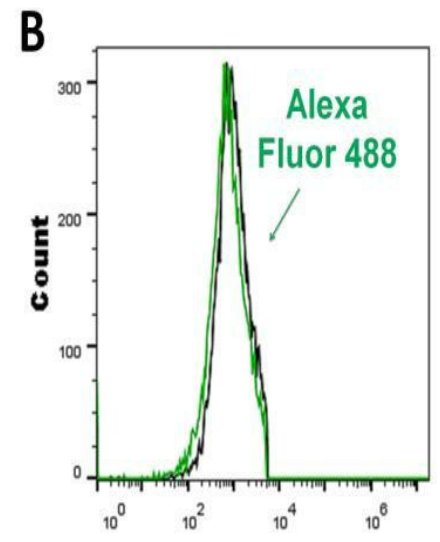

FL1-H : FL1-H
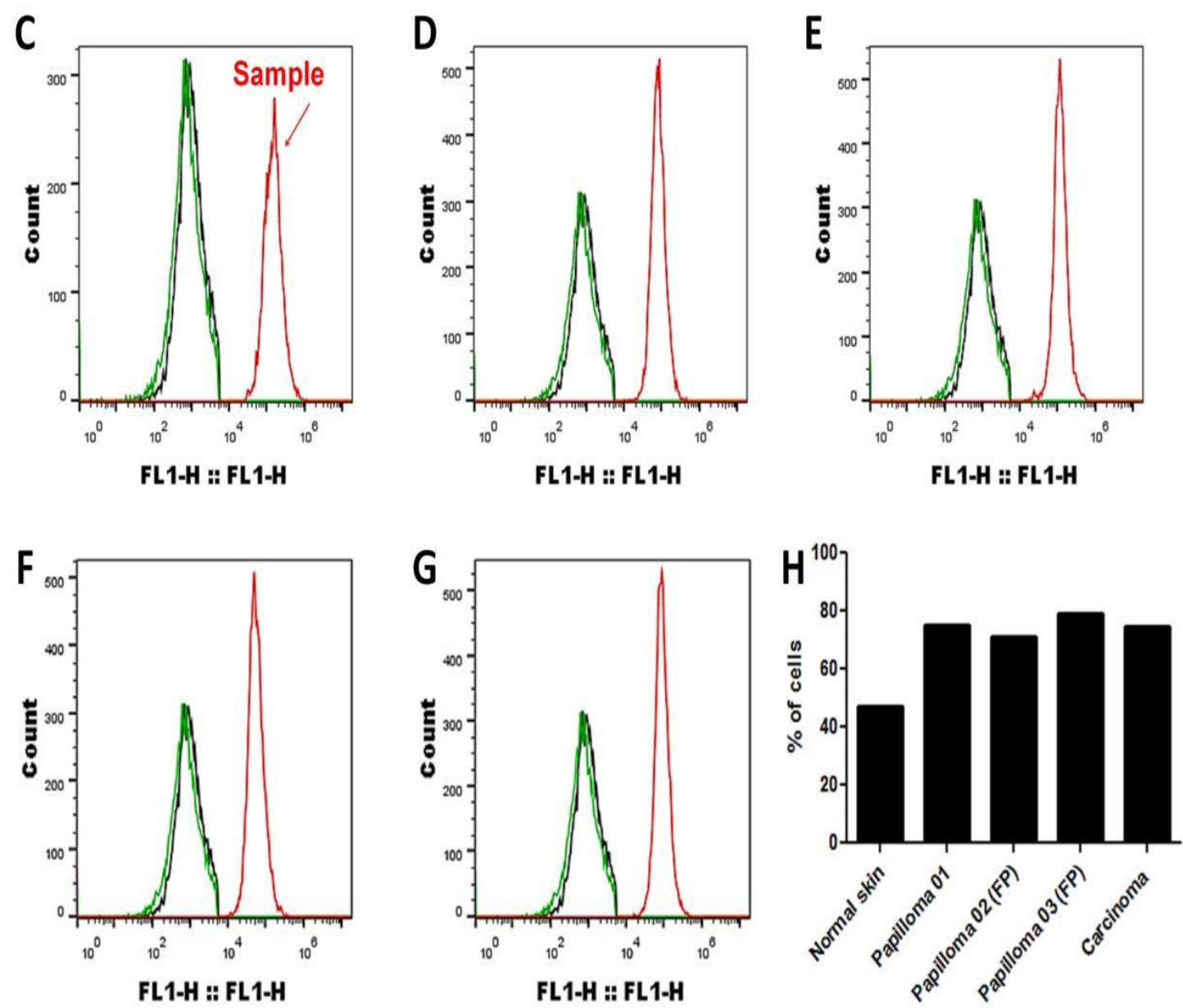

A) skin papilloma cells without any antibody; B) skin papilloma cells incubated with secondary antibody Alexa Fluor 488, showing absence of unspecific labelling; Oct-3/4 expression levels in: normal skin (C, BPV-free), skin papilloma (D, papilloma 01), fibropapilloma (E, papilloma 02 and F, papilloma 03) and G) esophageal carcinoma cell lines. H) Histogram based on the cell percentage expressing the Oct-3/4 transcription factor. Results show an increase in Oct-3/4 expression levels in BPVinfected cell lines. Cell analyzed in second passage (P2). Total of 10,000 events analyzed. 
Figure 3- Immunodetection of Oct-3/4 transcription factor

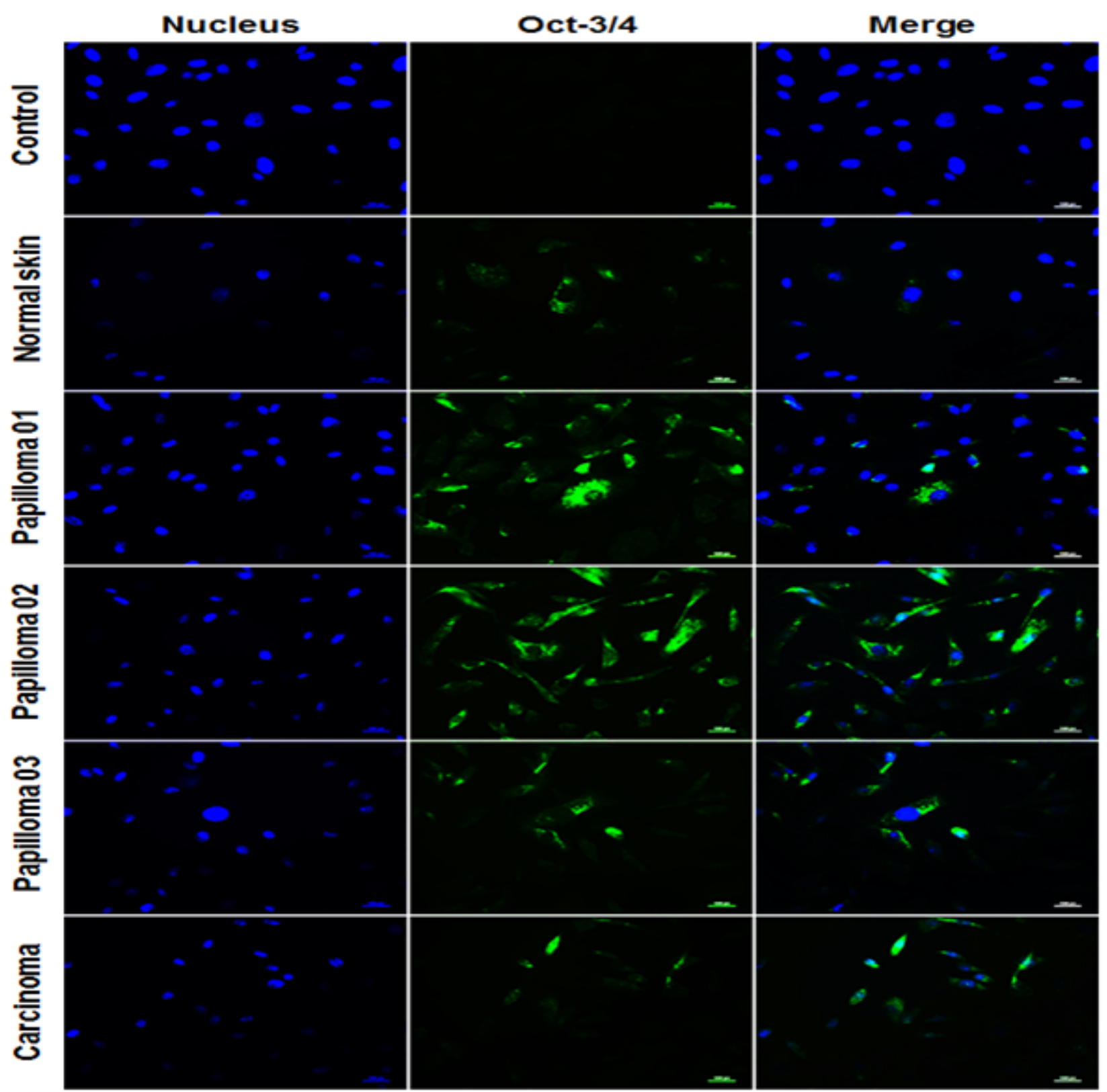

Immunodetection of Oct-3/4 transcription factor showing the increase of fluorescence signal in skin papilloma (papilloma 01), fibropapilloma (papilloma 02 and 03) and esophageal carcinoma cell lines. Results also show the nuclear labelling of Oct$3 / 4$ in esophageal carcinoma cells. Images obtained with total magnification of 400X, scale bar of $100 \mu \mathrm{m}$. 
Figure 4 - Morphological analysis by phase contrast analysis

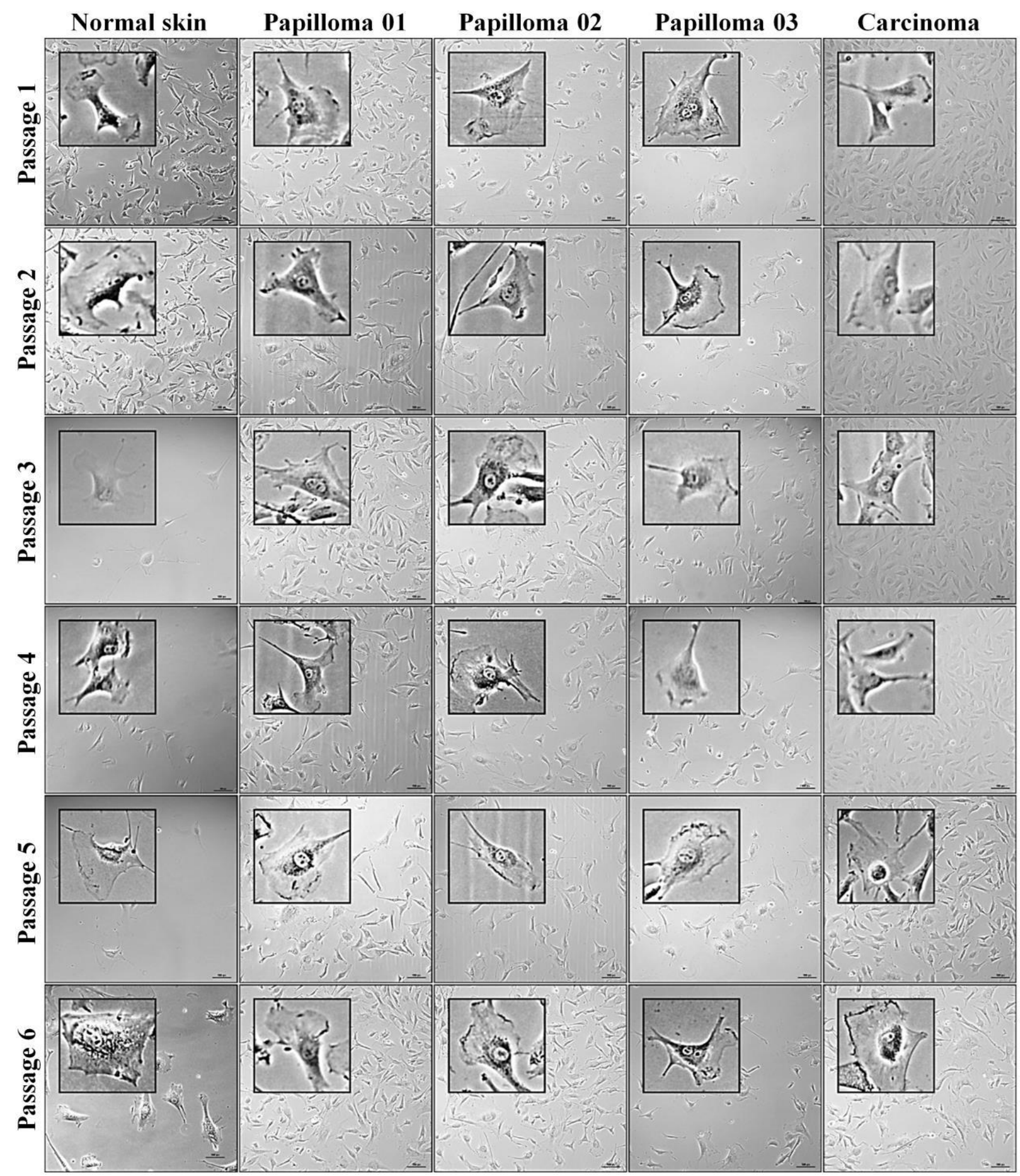

Phase contrast analysis showing the maintenance of cell polarity along the six passages of normal skin cell line (BPV-free) and the loss of cell polarity in all passages analyzed of skin papilloma (papilloma 01), fibropapilloma (papilloma 02 and 03 ) and esophageal carcinoma cell lines. All BPV-infected cell lines show the presence of lamellipodia and filopodia, suggesting the acquisition of migratory phenotype. Imagens obtained in total magnification of 100X, scale bar of $100 \mu \mathrm{m}$. 
Figure 5 - F-actin labelling

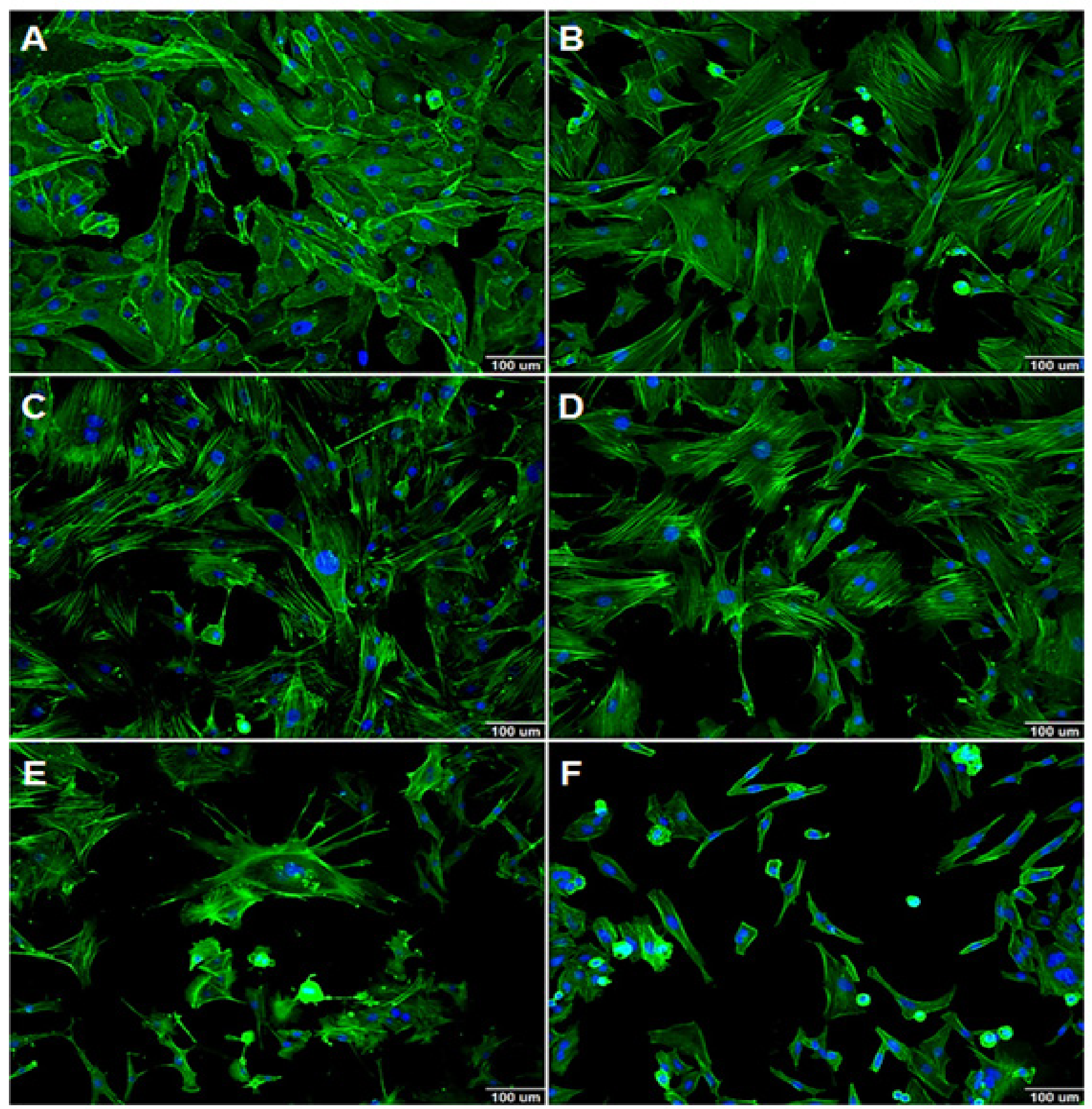

A) BPV-free normal skin, B) cutaneous papilloma, C) firbopapilloma 01, D) fibropapilloma 02, E and F) esophageal carcinoma. Results show the F-actin labelling in plasmatic membrane, reinforcing the presence of filopodia in all primary cultures cells derived from BPV-infected neoplasm. 
Figure 6 - Screen electron-micrograph (SEM)
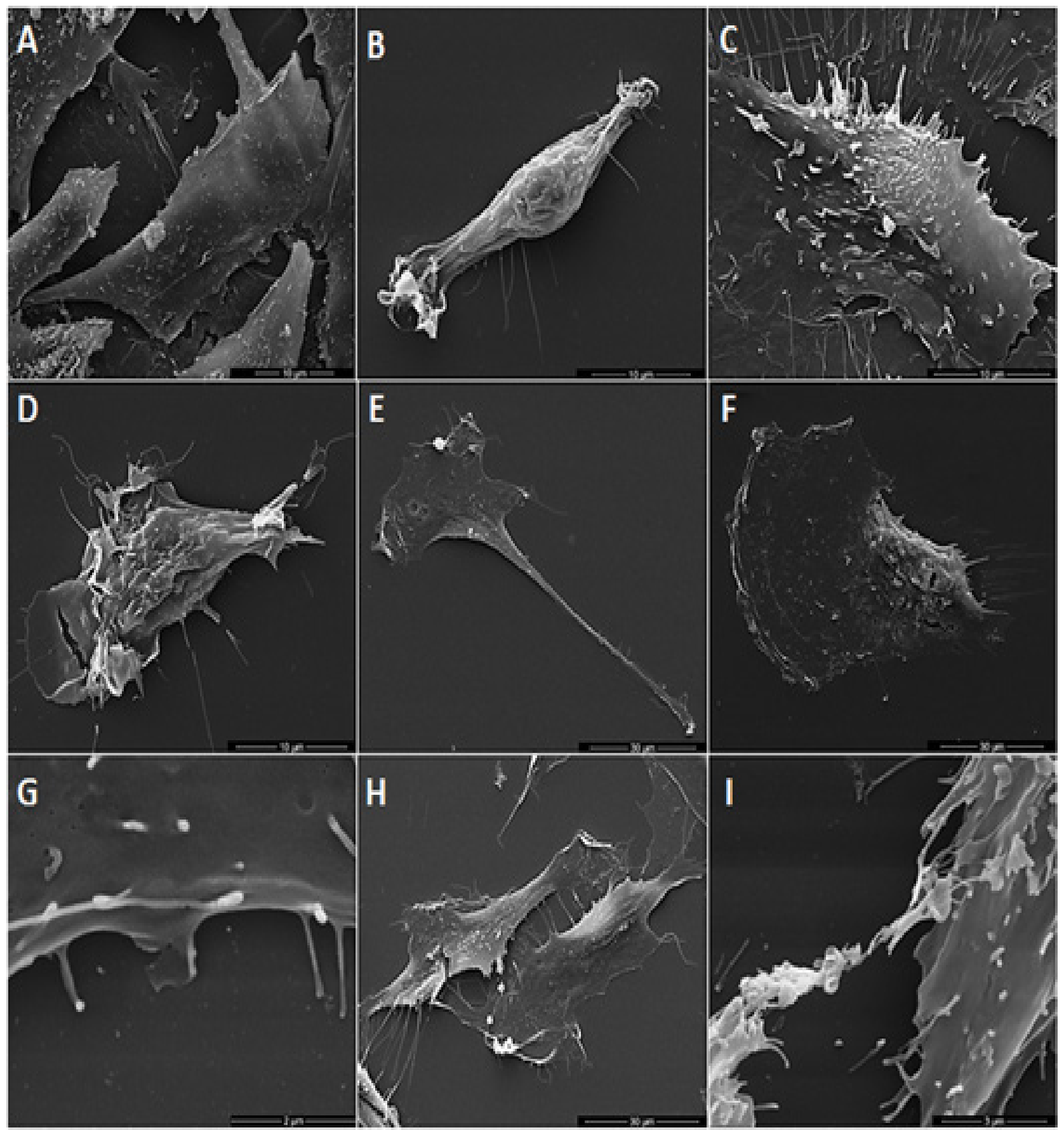

A) keratinocyte-like of normal skin cell line, presenting apical-basal polarity (6664 X), B) fibroblast-like of normal skin cell line, showing fusiform morphology ( $8280 \mathrm{X}$ ), cells of papilloma 01 (C, $9829 \mathrm{X}$, skin papilloma), 02 (D, $9388 \mathrm{X}$, fibropapilloma), 03 (E, 2893 X, fibropapilloma), and esophageal carcinoma (F, $2898 \mathrm{X}$ ) cell lines showing loss of polarity, extensive lamellipodia, and abundant filopodia, G) lamellipodia site, with filopodia, observed in esophageal carcinoma cell line (53021 $\mathrm{X})$, inter-cytoplasmic bridges observed in papilloma 02 (H, $3210 \mathrm{X})$, and esophageal carcinoma cell lines (I, $25777 \mathrm{X})$. 
Figure 7 - Results of cell migration assay by time-lapse video microscope
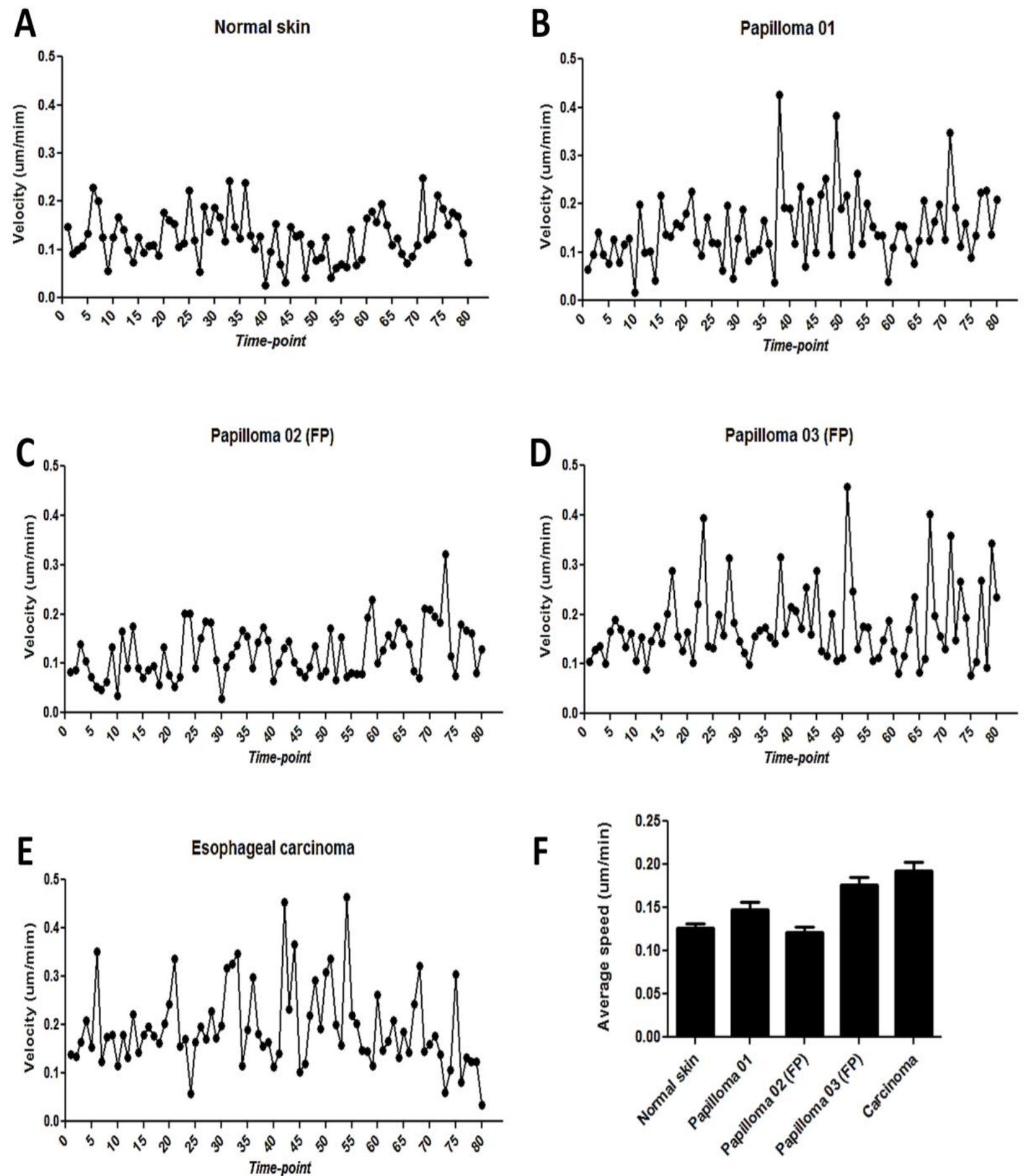

Results of cell migration assay by time-lapse video microscope showing the average speed in $\mu \mathrm{m} /$ minute in 80 time-point, in a total of 20 hours of analysis: A) normal skin, B) papilloma 01 (skin papilloma), C) papilloma 02 (fibropapilloma), D) papilloma 03 (fibropapilloma) and E) esophageal carcinoma cell lines. F) Histogram based on mean of cell velocity along the 80 time-point analyzed, followed by the standard deviation (bars) demonstrating the highest migration velocity in carcinoma cell line. Papilloma 01 and 03 show intermediated migration velocity, as confirmed by the Tukey's test. Normal skin and papilloma 02 did not reveal statistical difference between their migration velocity. 
Considering this result, we performed the Tukey's multiple comparison test (table 2), which showed that primary cultures derived from esophageal carcinoma and papilloma 03 (fibropapilloma) showed the highest migration velocity, indicating the acquisition of migratory phenotype. Papilloma 01 (skin papilloma) showed an intermediated migration velocity (table 2), while papilloma 02 (fibropapilloma) and normal skin did not show statistical difference, presenting the lower migration velocity.

\begin{tabular}{|l|l|l|l|}
\hline Multiple comparison & Mean Difference & $\mathrm{q}$ & $\mathrm{P}<0.05$ \\
\hline Normal skin and papilloma 01 & -0.02171 & 2.818 & No \\
\hline Normal skin and papilloma 02 (FP) & 0.004682 & 0.608 & No \\
\hline Normal skin and papilloma 03 (FP) & -0.04973 & 6.457 & Yes \\
\hline Normal skin and esophageal carcinoma & -0.06675 & 8.666 & Yes \\
\hline Papilloma 01 and Papilloma 02 (FP) & 0.02639 & 3.426 & No \\
\hline Papilloma 01 and Papilloma 03 (FP) & -0.02803 & 3.639 & No \\
\hline Papilloma 01 and esophageal carcinoma & -0.04504 & 5.848 & Yes \\
\hline Papilloma 02 (FP) and papilloma 03 (FP) & 7.065 & Yes \\
\hline Papilloma 02 (FP) and esophageal carcinoma & -0.05441 & 9.274 & Yes \\
\hline Papilloma 03 (FP) and esophageal carcinoma & -0.07143 & 2.209 & No \\
\hline
\end{tabular}

Table 2 - Result of Tukey's multiple comparison test FP - fibropapilloma

\section{Discussion}

Although recognized as oncogenic viruses [5], the PVs action following cancer initiation remains unclear [6]. This because little attention has been given to primary cell cultures derived from BPV-infected tissues. However, in last decades, studies have been shown productive infection in sites not passive of cell differentiation, such as placenta [25] and peripheral blood $[11,26]$, indicating the need to review the PVs natural history [5]. Moreover, since 2008 our group has been explored the potential of primary cell cultures as model to study the BPV pathology [27]. We already demonstrated that in vitro models present cytogenetic aberrations [9] similar to those verified in vivo $[1,28,29]$. Currently we also verified that primary cultures derived from skin papilloma, fibropapillomas and EC present glycolytic metabolic deregulation [7]. Similar results were also observed in cell cultures derived from equine sarcoid [30]. Despite these advances, the PVs action during metastasis remains unclear. Thus, we analyze the acquisition of stem-cell and migratory phenotype in primary cell cultures derived from skin papilloma, fibropapilloma and esophageal carcinoma. In this pioneering study, we verified the presence of tumorspheres in all BPV-infected primary cell cultures, but not in normal skin cells (figure 1). We also observed an increase in Oct-3/4 transcription factor in primary cultures derived from BPV-infected tissues in relation to normal skin cells (figure 2). These results suggest that BPV-infected cells present biological reprograming, leading to stem-cell phenotype acquisition.
Considering that stem-cells are inducible by increasing genomic instability [31], BPV E6 oncoprotein has a central role in biological reprograming process, once this oncoprotein induces genotoxicity and clastogenesis [32]. Moreover, studies have showed that both BPV [7] and HPV E6 promote oxidative stress, increasing the reactive oxygen species (ROS) production [33]. The E6 pro-oxidant activity can lead to PI3K and Akt phosphorylation, resulting in Oct-3/4 activation [23], justifying the nuclear labelling of this transcription factor verified in esophageal carcinoma cells (figure 3 ). Once activated, the Oct-3/4 binds to AGTCAAAT motif sequence present in target genes, contributing to stem-cell phenotype maintenance [34], as well as leading to apoptosis resistance. In this regard, the E6 oncoprotein promotes the p53 downregulation, avoiding the Bax protein translocation from Golgi complex to mitochondria, conferring an additional anti-apoptotic mechanism [35]. The apoptosis resistance is crucial to guarantee the survival during cell migration. Considering the biology of metastatic process, in which cancer cells are continuously exposed to different selective pressures during the migration process, the acquisition of apoptosis resistance is mandatory to guarantee the cell survival. For this reason, during the EMT is expected the acquisition of CSC-like phenotype [20]. However, the main characteristic of EMT is the loss of cell adhesion as a consequence of biochemical and genetics reprograming that lead to mesenchymal phenotype acquisition [36]. These reversible alterations confer invasiveness and migratory capability to cancer cells [37], allowing then to reach and colonize distant organs, resulting in metastasis. Based on these data, we also analyzed the acquisition of migratory phenotype as additional evidences of EMT. 
Our results showed the loss of apical-basal polarity in skin papilloma, fibropapilloma and esophageal carcinoma cells (figure 4). This morphological alteration was not verified in normal skin cells (figure 4). In addition, we observed the presence of lamellipodia and filopodia in all BPV-infected primary cell cultures (figure 4). These protrusions were also verified by SEM analysis (figure 6).

Filopodia are transient organelles with $0.1-0.2 \mu \mathrm{m}$, composed by F-actin monomers, asymmetrically and perpendicularly to lamelipodia, being associated to cell migration $[38,39]$. Therefore, we also verified the F-actin labelling in lamelipodia sites (figure 5), confirm the results of phase contrast (figure 4) and screen electron microscopy (figure 6). The F-actin labelling in lamelipodia sites was observed in skin papilloma, fibropapilloma and esophageal carcinoma cells (figure 5), suggesting that BPV interacts with cytoskeleton, leading to filopodia formation. However, further evidences are necessary to better understand this interaction.

Based on the morphological analysis, we verified the cell velocity migration by time-lapse video microscopy. Results showed that papilloma 03 (fibropapilloma) and esophageal carcinoma cells presented the highest average speed, indicating the acquisition of migratory phenotype (figure 7, table 2). Papilloma 01 (skin papilloma) showed an intermediated migration velocity (figure 7, table 2). Normal skin and papilloma 02 (fibropapilloma) did not show statistical difference (figure 7, table 2).

We also observed the presence of inter-cytoplasmic bridges in skin papilloma (figure 6C), fibropapilloma (figure 6H) and esophageal carcinoma cells (figure 3I). Although little attention has been given to these structures, they can acts as vehicle of horizontal genetic transfers, since DNA sequences were already described into these inter-cytoplasmic bridges [40]. Considering that BPV genome is found in epissomal form, these bridges can contribute to the maintenance of BPV DNA sequences along the six passages, as previous described by us using these same cell cultures [7].

In summary, our results demonstrate that primary culture derived from PVs-infected lesions can be useful models to study the viral pathology, showing BPV as an inducer the stem-cell phenotype acquisition and cell migration. These data combined to the cell metabolic deregulation, already verified with the same in vitro model [7], are important evidences for papillomavirus infection as a relevant EMT promoter.

\section{Acknowledgement}

The authors thank the Fundação de Amparo à Pesquisa do Estado de São Paulo (FAPESP, process 2014/20617-5) and Fundação Butantan by the financial support.

\section{References}

1) Stocco dos Santos RC, Lindsey CJ, Ferraz OP, Pinto JR, Mirandola RS et al. (1998) Bovine papillomavirus transmission and chromosomal aberrations: an experimental model. J Gen Virol 79: 2127-2135.

2) Araldi RP1, Melo TC, Neves AC, Spadacci-Morena DD, Magnelli Ret al. (2015) Hyperproliferative action of bovine papillomavirus (BPV): Genetics and histopathological aspects. Genet Mol Res 14: 12942-12954.

3) Araldi R, Assaf S, Carvalho R, et al. (In press.) Papillomaviruses: a systematic review. Genet Mol Biol.

4) Araldi R. Bovine Papillomavirus: (2015) What We Know and What We Should Know. (Araldi R, ed.). Lambert Academic Publishing.

5) Munday Js (2014) Bovine and human papillomaviruses: a comparative review. Vet Pathol 51:1063-1075.

6) Araldi RP, Módolo DG, de Sá Júnior PL, Consonni SR, de Carvalho RF, et al. (2016) Genetics and metabolic deregulation following cancer initiation: A world to explore. Biomed Pharmacother 82:449-458.

7) Araldi R, De-Sá-Júnior P, Magnelli R, et al. (2016) Primary cultures derived from bovine papillomavirus-infected lesions as model to study metabolic deregulation. J Cancer Res Ther Oncol. 4:1-18.

8) Borzacchiello G, Roperto F (2008) Bovine papillomaviruses, papillomas and cancer in cattle. Vet Res. 39: 45.

9) Campos SR, Melo TC, Assaf S, Araldi RP, Mazzuchelli-de-Souza J, Sircili MP, Carvalho RF, et al. (2013) Chromosome aberrations in cells infected with bovine papillomavirus: comparing cutaneous papilloma, esophagus papilloma, and urinary bladder lesion cells. ISRN Oncol.

10) 10) Araldi R, Melo T, Diniz N, Carvalho R, Beçak W, et al. ( 2013) Bovine papillomavirus clastogenic effect analyzed in comet assay. Biomed Res Int.

11) Melo TC, Araldi R, Pessoa N, de-Sá-Júnior PL, Carvalho RF, et al. (2015) Bos taurus papillomavirus activity in peripheral blood mononuclear cells : demonstrating a productive infection. Genet Mol Res. 14:16712-16727.

12) Calinisan J, Chan S, King A, Chan P (2002) Human papillomavirus and blastocyst apoptosis. J Assist Reprod Genet. 19: 132-136.

13) Adam ML, Pini C, Tulio S, Cantalice JC, Torres RA, et al. (2015) Assessment of the association between micronuclei and the degree of uterine lesions and viral load in women with human papillomavirus. Cancer Genomics Proteomics 12: 67-71.

14) Fidler IJ (2003) The pathogenesis of cancer metastasis: the "seed and soil" hypothesis revisited. Nat Rev Cancer 3: 453-458.

15) Lee J, Dedhar S, Kalluri R, Thompson E (2006) The epithelialmesenchymal transition: new insights in signaling, development, and disease. J Cell Biol 172: 973-981.

16) Pasi C, Dereli-Öz A, Negrini S, Friedli M, Fragola G, et al. (2011) Genomic instability in induced stem cells. Cell Death Differ 18:745753.

17) Argyle D, Blacking T (2008) From viruses to cancer stem cells: Dissecting the pathways to malignancy. Vet J 177: 311-323.

18) Widschwendter M, Fiegl H, Egle D, Mueller-Holzner E, Spizzo G, et al. ( 2007) Epigenetic stem cell signature in cancer. Nat Genet 39: 157-158.

19) Massagué J, Obenauf A (2010) Metastatic colonization by circulating tumor cells. Science 80: 5 .

20) Marcucci F, Stassi G, De Maria R ( 2016) Epithelial-mesenchymal transition: a new target in anticancer drug discovery. Nat Rev Drug Discov 1-15. 
21) Araldi RP, Giovanni DN, Melo TC, Diniz N, Mazzuchelli-de-Souza J et al. (2014) Bovine papillomavirus isolation by ultracentrifugation. J Virol Methods 208: 119-124.

22) Borzacchiello G, Ambrosio V, Roperto S, Poggiali F, Tsirimonakis E, et al. (2003) Bovine papillomavirus type 4 in oesophageal papillomas of cattle from the South of Italy. J Comp Pathol 128: 203-206.

23) Moore N, Houghton J, Lyle S ( 2012) Slow-cycling therapy-resistant cancer cells. Stem Cells Dev 21:1822-1830.

24) Weiswald L, Bellet D, Dangles-Marie V (2015) Spherical cancer models in tumor biology. Neoplasia $17: 1-15$. .

25) Roperto S, Borzacchiello G, Esposito I, et al. (2012) Productive infection of bovine papillomavirus type 2 in the placenta of pregnant cows affected with urinary bladder tumors. PLoS One 7: 1-9.

26) Roperto S, Comazzi S, Ciusani E, et al. (2011) PBMCs are additional sites of productive infection of bovine papillomavirus type 2. J Gen Virol 92: 1787-1794.

27) Campos SR1, Trindade C, Ferraz OP, Giovanni DN, Lima AA, et al. ( 2008) Can established cultured papilloma cells harbor bovine papillomavirus? Genet Rolecular Res 7: 1119-1126.

28) Melo TC, Diniz N, Campos SR, Ferraz OP, Rieger TT, et al. (2011) Cytogenetic studies in peripheral blood of bovines afflicted by papillomatosis. Vet Comp Oncol 9: 269-274.

29)Simões R, Barth O (2016) Chromosome aberrations as a biomarker for genomic instability In cell cultures originated from bovines, canines and equines infected with papillomavirus. Int J Appl Sci Biotechnol 4: 104-112.

30) Potocki L, Lewinska A, Klukowska-Rötzler J, Bielak-Zmijewska A, et al.(2014) Sarcoid-derived fibroblasts: links between genomic instability, energy metabolism and senescence. Biochimie 92: 163-172.

31) Liang Y, Zhong Z, Huang Y, Deng W, Cao J, Tsao G, et al. (2010) Stem-like cancer cells are inducible by increasing genomic instability in cancer cells. J Biol Chem 285: 4931-4940.

32) Araldi RP, Mazzuchelli-de-Souza J, Modolo DG, de Souza EB, de Melo TC, et al. (2015) Mutagenic potential of Bos taurus papillomavirus type 1 E6 recombinant protein : First description. Biomed Res Int.

33) Williams V, Filippova M, Filippov V, Payne K, Duerksen-Hughes P.(2014) Human papillomavirus type $16 \mathrm{E}^{\star}$ induces oxidative stress and DNA damage. J Virol 88: 6751-6761.

34) Pan G, Chang Z, Schöler H, Pei D (2002) Stem cell pluripotency and transcription factor Oct4. Cell Res 12: 321-329.

35) TeSlaa T, Setoguchi K, Teitell M (2016) Mitochondria in human pluripotent stem cell apoptosis. Semin Cell Dev Biol 76-83.

36) Qi X, Zhang L, Lu X (2016) New insights into the epithelial-tomesenchymal transition in cancer. Trends Pharmacol Sci 37: 246-248.

37) Cichon M, Nelson C, Radisky D (2015) Regulation of epithelialmesenchymal transition in breast cancer cells by cell contact and adhesion. Cancer Inform 14: 1-13.

38) Mattila P, Lappalainen P. (2008) Filopodia: molecular architecture and cellular functions. Nat Rev 9: 446-454.

39) Meyen D, Tarbashevich K, Banisch TU, Wittwer C, ReichmanFried M, et al. (2015) Dynamic filopodia are required for chemokinedependent intracellular polarization during guided cell migration in vivo. Elife 4: e05279.

40) Schulze E, Blose S (1984) Passage of molecules across the intercellular bridge between post-mitotic daughter cells. Exp Cell Res 151: 367-373.
Submit your manuscript to a JScholar journal and benefit from:

ฯ Convenient online submission

ฯ Rigorous peer review

I Immediate publication on acceptance

ฯ Open access: articles freely available online

I High visibility within the field

ๆ Better discount for your subsequent articles

Submit your manuscript at

http://www.jscholaronline.org/submit-manuscript.php 